\title{
IFC-CENTRIC VEGETATION MODELLING FOR BIM
}

\author{
Gobeawan L. ${ }^{1 *}$, Lin S. E. ${ }^{\dagger \dagger}$, Liu X. ${ }^{1}$, Wong S. T. ${ }^{1}$, Lim C. W. ${ }^{1}$, Gaw Y-F. L. ${ }^{3}$, Wong N. H. ${ }^{2}$, Tan P. Y. ${ }^{2}$, Tan C. L. ${ }^{2}$, He Y. ${ }^{2}$ \\ ${ }^{1}$ Institute of High Performance Computing, Singapore \\ ${ }^{2}$ National University of Singapore, Singapore \\ ${ }^{3}$ National Parks Board, Singapore
}

KEY WORDS: BIM authoring software, IFC interface, 3D parametric modeling, plant representation, plant shapes, plant species.

\begin{abstract}
:
There has been a growing interest in integrating vegetation into the built environment in order to ameliorate the negative effects of increasing urbanisation. In Singapore, government policies encourage the inclusion of skyrise greenery into new and existing buildings. To further streamline workflows, statutory BIM (Building Information Modelling) submissions in architecture, engineering and construction (AEC) industries have been mandated. However, landscape plans are still excluded from these BIM submissions due to the lack of a centralised vegetation database and the absence of a standardised BIM format for landscape architectural submissions. This paper presents a streamlined methodology for creating and using a centralised vegetation library for landscape architects. The workflow leverages off the Industry Foundation Classes (IFC) standard for data exchange regardless of the BIM authoring software used and provides a framework of four operational modules: an expandable and low-maintenance species-level vegetation library, a BIM authoring workflow that allows inclusion of vegetation objects, an IFC interface, and a lightweight 3D vegetation model generator. This paper also showcases a use-case of embedding information-enriched 3D vegetation objects into a simulated landscape plan. The proposed workflow, when adopted in AEC industries, will enable governing agencies to track diverse greening efforts by the industry and to potentially include other measurements such as cooling performance or maintainability.
\end{abstract}

\section{INTRODUCTION}

\subsection{Motivation}

Along with urban developments around the world, there is a constant desire to conserve greenery in the urban environment for environmental and ecological benefits (Nyuk Hien et al., 2007) as well as recreational, aesthetic and even therapeutic ones (Uijtdewilligen et al., 2019). However, traditionally in urban planning, buildings are commonly separated from vegetated landscapes, and both would typically compete for the same site coverage. In the land-scarce Singapore, this conflict has led to regulations, incentives, and innovations that promote the integration of vegetation into the built environment (Neo et al., 2012). Architecturally, this has manifested as sky gardens (rooftop greenery) and vertical greening systems - collectively coined as "skyrise greenery" (Tan and Chiang, 2009). Skyrise greenery is now seen as a means to promote biodiversity while simultaneously targetting socio-political and tourism-marketing goals of Singapore (Sini, 2020). This has been so widespread that the Singapore government has set a target to double the total area of skyrise greenery to 200ha by year 2030 (Ng and Nathan Charles, 2017).

On the other hand, in order to better streamline the design to the construction process especially for increasingly complex architectural projects, Singapore has mandated submissions of architectural and construction drawings in the BIM format (BCA, 2016b). The unified BIM approach across AEC industries will potentially improve the construction productivity, the level of integration, as well as the collaboration across various disciplines (BCA, 2013). However, unlike architectural and engineering plans, landscape plans in Singapore are still being submit-

\footnotetext{
* Corresponding author: gobeawanl@ihpc.a-star.edu.sg

$\dagger$ Corresponding author: akilse@nus.edu.sg
}

ted outside the BIM environment (BCA, 2016a), hence the potential engineer-architect collaboration benefits of the BIM environment are unattainable, and landscape architects are risked being removed from the supply chain altogether (Ahmada and Aliyua, 2012).

The push for adopting the BIM approach in the skyrise greening requires a multitude of currently non-established workflows, guidelines, technicalities, knowledge. This is further burdened by the lack of motivation, competence and time by workers, the absence of support by management for training and education, the non-existent client demand for BIM submissions, as well as a lack of standards instituted by governing bodies (Chan, 2014, Siebelink et al., 2021). However, landscape architects still advocate for a BIM adoption across the industry (Schmidt, 2016, Ackerman, 2019) through BIM working groups (Landscape Institute, 2019). In practice, including BIM into existing landscape planning workflow is challenging for landscape architects, as it involves a complex concoction of various software solutions and the creation of custom libraries. Moreover, most BIM authoring software have not catered for landscape architectural works, and as such, landscape architects lack the tools and libraries to operate in a proper BIM workflow (Flohr, 2011, Sipes, 2014).

To address this, a number of plug-ins have been developed for specific BIM authoring software. These include CS ArtisanRV and Environment plugins for Autodesk Revit or Land F/X and Lands Design for Rhinoceros and Autodesk AutoCAD. In addition, a purpose-built variant of Vectorworks (Vectorworks Landmark) was also developed specifically for landscape architects. However, one caveat of these solutions is the need to subscribe to one particular software, preventing a conformed practice at the national level with a centralised database.

In addition, the systematic information collection of landscape elements, especially vegetation, remains a significant challenge 
for the industry (Abdirad and Lin, 2015). Existing vegetation libraries within BIM authoring software are either too limited in species variety or lack of tropical species. While individual landscape architectural practices might generate and maintain their own customised vegetation models or adopt third party libraries, to do so without any governing BIM standards might not be scalable in the long run. For example, the National Building Specification (NBS) National BIM Library of United Kingdom, which hosts thousands of BIM objects according to the NBS BIM Object standards, does not consist of a single plant object (NBS, 2021), while other online libraries with individually modelled trees and shrubs are limited to a handful of pregenerated non-tropical species (Graphisoft, 2021).

At present, Singapore has a centralised, public vegetation library, created and maintained by National Parks Board (NParks) Flora \& Fauna Web (FFW) (NParks, 2021), which contains exceptional botanical details of over 4000 plant species, albeit lacking of spatial information. It is however anticipated that the FFW database, or other similar vegetation databases, can be extended to include more spatial attributes to generate speciesspecific 3D BIM vegetation models for the industry.

Hence, this paper presents a technical workflow of creating such information-rich vegetation models, based off a centralised database, within a BIM environment at the national level for a Singaporean context. This workflow leverages off the Industry Foundation Classes (IFC) standard for openBIM data exchange (buildingSMART, 2021), providing the flexibility of not requiring users to subscribe to a particular BIM authoring software.

\subsection{Objectives and Potential Contributions}

With the above motivations, the objective of our work is to develop a methodology leveraging off the IFC standard in order to generate lightweight, information-rich BIM vegetation models at the species-level, for a unified national vegetation database. Specifically, the objectives are as follows.

1. To define parameters for the vegetation library

2. To develop a unified workflow within various commercial BIM authoring software using IFC standards

3. To develop an IFC interface that connects the BIM authoring software, vegetation library, and 3D model generation

(a) To extract parameter data from vegetation library as specified in an IFC file containing placeholders and constraints from BIM authoring software

(b) To pass parameters, placeholders, and constraints to $3 \mathrm{D}$ vegetation model generation and placement

(c) To embed $3 \mathrm{D}$ vegetation models into the IFC file and return it to the BIM authoring software

4. To automatically generate $3 \mathrm{D}$ vegetation models based on input parameters

5. To automatically place vegetation models onto IFC placeholders within constraints

The proposed methodology to achieve these objectives will potentially be an efficient and extendable way to create and maintain a centralised species-level database, independent of any specific BIM authoring platforms. The methodology includes a vegetation library with spatial parameters and BIM vegetation object types, a BIM authoring workflow and an IFC interface along with the technical 3D model generation and placement.

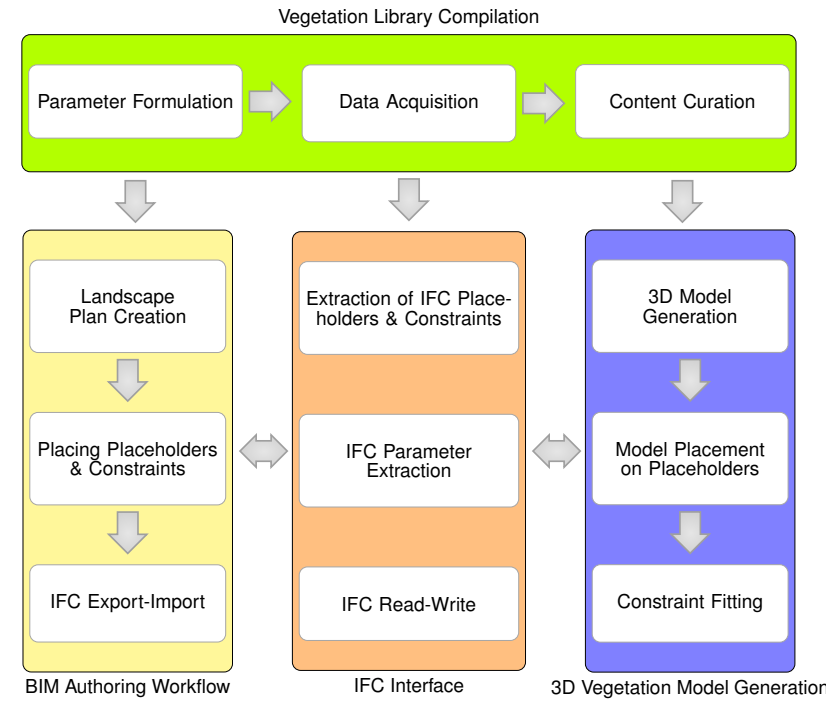

Figure 1. Proposed methodology workflow for IFC-centric vegetation modelling for BIM

This paper demonstrates the proposed workflow methodology in the context of Singapore. However, the workflow is also applicable to other cities given their species spatial parameters obtained by field measurements or observations. The lightweight nature of the simplified BIM vegetation models produced in this workflow allow for a computationally efficient means to model these objects while simultaneously accommodating non-spatial parameters (defined by landscape architects or central governing agencies).

\section{METHODOLOGY}

We develop a workflow to generate and embed simplified, spatially-representational vegetation models into BIM based on a set of parameter values defined by a user in a BIM authoring software. The model generation takes a similar parameterbased approach for low- and high-resolution CityGML tree models on a large scale (Gobeawan et al., 2018, Gobeawan et al., 2019, Gobeawan et al., 2021), except that in this workflow, the vegetation models are low-resolution yet generated based on different parameter values for each species.

This workflow comprises four interrelated modules (Figure 1), namely the vegetation library compilation (Section 2.1), BIM authoring workflow (Section 2.2), IFC interface (Section 2.3), and $3 \mathrm{D}$ vegetation model generation (Sections 2.4.1, 2.4.2 \& 2.4.3). Each module can be maintained or updated independently by different stakeholders: the vegetation library by an authorised regulatory agency, the BIM authoring workflow by landscape architects and the IFC interface and 3D vegetation model generation by the software developer.

\subsection{Vegetation Library Compilation}

To develop a centralised vegetation library, we identified and compiled spatial parameters required to control the size and shape of a vegetation object at its crown and/or trunk as well as the typical planting distance of the species, if any. These spatial parameters are explained in Table 1, where some parameters govern the overall size or distribution of the vegetation 
(Figure 2), while others define the crown shape of the vegetation (Figure 3). Different value combinations of these parameters generate various major tree shapes to represent vegetation species (Figure 4). The simplicity of these spatial parameters enables the 3D model generation by the inputs of field measurements or expert opinions. Table 2 provides an example of a few species along with their spatial parameters.

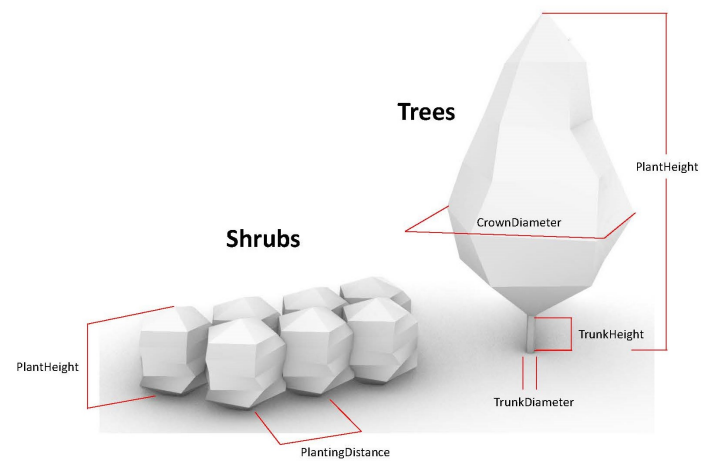

Figure 2. PlantHeight, PlantingDistance, TrunkDiameter, TrunkHeight parameters affect the size or distribution.

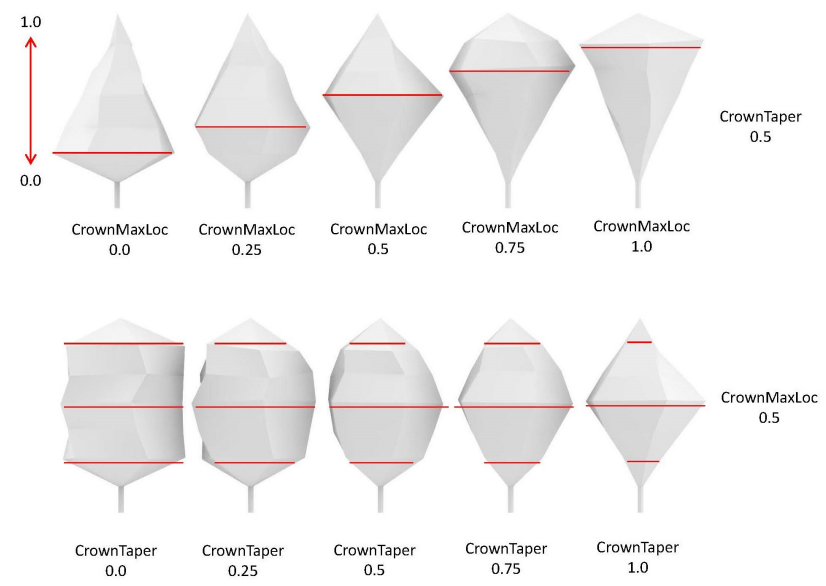

Figure 3. CrownMaxLoc and CrownTaper parameters affect the crown shape.

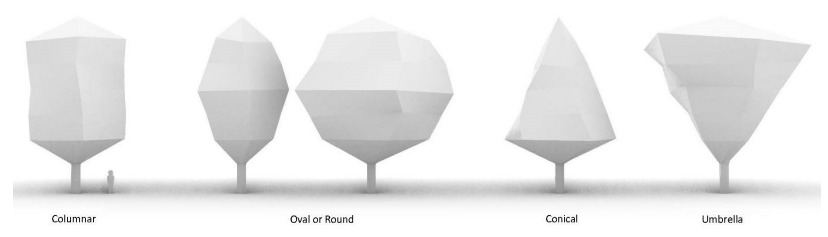

Figure 4. Combining the spatial parameters allow for a majority of crown shapes to be represented.

In addition to the spatial parameters which govern the physical shape of the vegetation objects, non-spatial parameters can also be embedded into the vegetation objects. Table 2, for example, has two non-spatial parameters, SpeciesCode and PlantType. SpeciesCode is a species identifier to link the BIM authoring software and the centralised vegetation library. PlantType indicates the vegetation type (tree, palm, shrub or others). Another example of non-spatial parameters is the Leaf Area Index (LAI) which is used to calculate Green Plot Ration (GnPR), which is the ratio of the average LAI to the total site area of the development (URA, 2017). The library curator may also define other non-spatial parameters with a prefix (Table 3). For example, CP_Cost would be a custom parameter $(\mathrm{CP})$ provided by the end user indicating costing while $N P L A I$ would indicate the LAI of the species.

\subsection{BIM Authoring Workflow}

The creation of a landscape plan starts with the creation of placeholders (Figure 5) within a BIM authoring software. A placeholder is a simple, temporary drawing which represents an object in a typical landscape plan, to be replaced with some 3D models later and was designed to mimic landscape drawing in 2D. A number of placeholder types to represent various plant types were established in each BIM authoring software. Within the two BIM authoring software tested in this paper (Autodesk Revit 2021 and ArchiCAD 24), there were no native methods to include areas of vegetation to symbolise areas to be planted with a specific species of shrubs, hence workarounds had to be developed in order to represent them in the BIM environment (Table 4).

This paper focuses on trees and shrubs, while other plant types are in development. Solitary trees and palms, for example, are represented as individual cylindrical placeholders, whereas shrubs, ground cover (e.g., grass) and vertical greening (e.g., green walls or climbers) are represented with volumetric placeholders. Here, the cylindrical placeholders represent the approximated crown diameter as well as the position of the tree or palm whereas the volumetric placeholders are meant to represent the soil volume under the area of shrubs being planted. Overlaps between the two placeholders are possible and in fact quite often the case both in landscape plans as well as in real world planting (e.g. the planting of a tree over a patch of grass or even within an area of planted shrubs). As such, there has not been a protocol coded in to actively identify and account for these overlaps as it was deemed unnecessary considering the plants themselves are likely to overlap in reality.

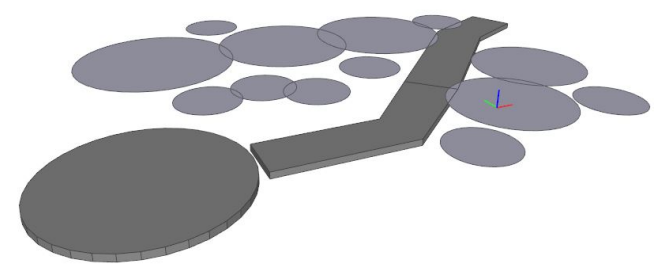

Figure 5. Placeholder objects exported as an IFC file for placing trees/palms (ground circle) and shrubs (ground volume).

Embedded in these placeholders are parameters SpeciesCode and PlantType (Figure 6) in order to identify a species from the vegetation library along with its plant type. This is necessary for some species which can be planted as solitary trees or shrubs, e.g., Syzygium myrtifolium. It will also enable different calculations of GnPR.

\subsection{IFC Interface}

The IFC interface converts, parses and translates data among the IFC file from a BIM authoring software, the vegetation library and the $3 \mathrm{D}$ vegetation model generator using the identifier SpeciesCode. The output of the IFC interface is informationenriched 3D vegetation models in IFC format, to be returned to the BIM authoring software (Figure 7). To achieve this, the IFC interface undertakes the following. 
Table 1. Spatial parameters to inform of the size and shape of plant objects

\begin{tabular}{lll}
\hline Spatial Parameter & Description & Plant Type \\
\hline PlantHeight & Height of plant & Tree or shrub \\
CrownDiameter & Diameter of crown & Tree or shrub \\
CrownMaxLoc & Vertical position within a crown where the diameter is at its maximum & Tree/palm or shrub \\
CrownTaper & Indicator of the difference between the minimum and maximum diameter of the crown & Tree/palm or shrub \\
TrunkHeight & Height of tree/palm trunk & Tree \\
TrunkDiameter & Diameter of tree/palm trunk & Tree \\
PlantingDistance & Horizontal planting distance between two shrub objects planted in the same area & Shrub \\
\hline
\end{tabular}

Table 2. A snippet of the vegetation library with some spatial and non-spatial parameter mean values

\begin{tabular}{|c|c|c|c|c|c|c|c|c|c|c|}
\hline No. & SpeciesName & 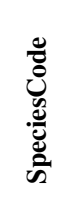 & 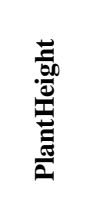 & 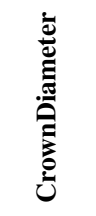 & 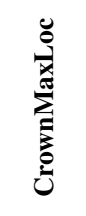 & 离 & 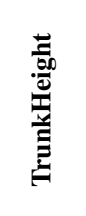 & 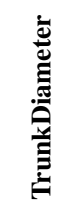 & 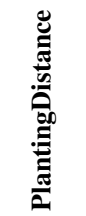 & 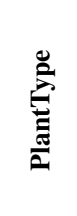 \\
\hline 1 & Alstonia scholaris & 1001 & 7.986 & 5.374 & 0.000 & 0.200 & 2.993 & 0.379 & N.A. & Tree \\
\hline 2 & Archontophoenix alexandrae & 1002 & 9.095 & 5.709 & 0.324 & 0.342 & 3.304 & 0.482 & N.A. & Palm \\
\hline 3 & Bucida molineti & 1003 & 7.689 & 5.322 & 0.356 & 0.320 & 1.122 & 0.235 & N.A. & Tree \\
\hline 4 & Cassia fistula & 1006 & 6.622 & 4.698 & 0.820 & 0.720 & 3.171 & 0.164 & N.A. & Tree \\
\hline 5 & Dalbergia oliveri & 1008 & 11.253 & 11.595 & 0.350 & 0.333 & 3.077 & 0.581 & N.A. & Tree \\
\hline 6 & Aglaia odorata & 9000 & 1.527 & 1.480 & 0.957 & 0.615 & N.A. & N.A. & 1.193 & Shrub \\
\hline 7 & Bauhinia kockiana & 9001 & 2.300 & 1.700 & 0.793 & 0.584 & N.A. & N.A. & 1.400 & Shrub \\
\hline 8 & Bougainvillea glabra & 9002 & 0.900 & 1.000 & 0.876 & 0.731 & N.A. & N.A. & 0.100 & Shrub \\
\hline 9 & Bougainvillea spp. & 9003 & 1.809 & 2.482 & 0.655 & 0.494 & N.A. & N.A. & 2.027 & Shrub \\
\hline 10 & Caesalpinia pulcherrima & 9004 & 1.200 & 1.300 & 0.728 & 0.597 & N.A. & N.A. & 0.700 & Shrub \\
\hline
\end{tabular}

Table 3. Examples of custom user parameters (CP) and NParks parameters (NP)

\begin{tabular}{llc}
\hline Parameter & Description & Author \\
\hline CP_Nursery & Nursery to procured from & User \\
CP_Cost & Cost per plant & User \\
CP_Phase & Phasing for planting & User \\
NP_LAI & Leaf Area Index & NParks \\
NP_Native & Native or exotic species & NParks \\
NP_Flower & Colour of flower & NParks \\
\hline
\end{tabular}

Table 4. Placeholder types in Revit and ArchiCAD

\begin{tabular}{llcc}
\hline Platform & Plant Type & Native Family & Geometry Type \\
\hline Revit & Tree or Palm & Custom Family & Cylinder \\
Revit & Shurbs & Floor Family & Slab Volume \\
ArchiCAD & Tree or Palm & Custom Object Favourites & Cylinder \\
ArchiCAD & Shurbs & Mesh Object Favourites & Mesh Volume \\
\hline
\end{tabular}

\begin{tabular}{|l|l|}
\hline Data & 3895.0 \\
\hline CrownDiameter & Palm \\
\hline PlantType & 1002 \\
\hline SpeciesCode & Archontophoenix alexandrae \\
\hline SpeciesName & AA \\
\hline SpeciesTag & \\
\hline \multicolumn{1}{|c|}{ PLANTING INFO } & 1002 \\
\hline J SpeciesCode & Archontophoenix alexandrae \\
\hline 5 SpeciesName & AA \\
\hline D SpeciesTag & Palm \\
\hline 5 PlantType &
\end{tabular}

Figure 6. Placeholders in both Revit (top) and ArchiCAD (bottom) require parameters SpeciesCode and PlantType.

1. Parsing placeholder parameters

2. Extracting placeholder geometry

3. Passing placeholder data to the model generator

4. Converting generated 3D models into IFC B-rep shapes

5. Inserting non-spatial parameters into the models

6. Exporting the information-enriched $3 \mathrm{D}$ vegetation models as an IFC file

\subsection{D Vegetation Model Generation}

2.4.1 Generating 3D Vegetation Models To generate the $3 \mathrm{D}$ vegetation models at runtime (Figure 8 ), a low-resolution base model in an OBJ format is customised based on the species-specific spatial parameter values in Table 1. These spatial parameters can be specified directly (by using a CP) or read from the vegetation library. To further reduce the number of polygons, the level of detail in the models correlates with crown size, i.e. plants with smaller crowns are represented by simpler models with fewer vertices. 


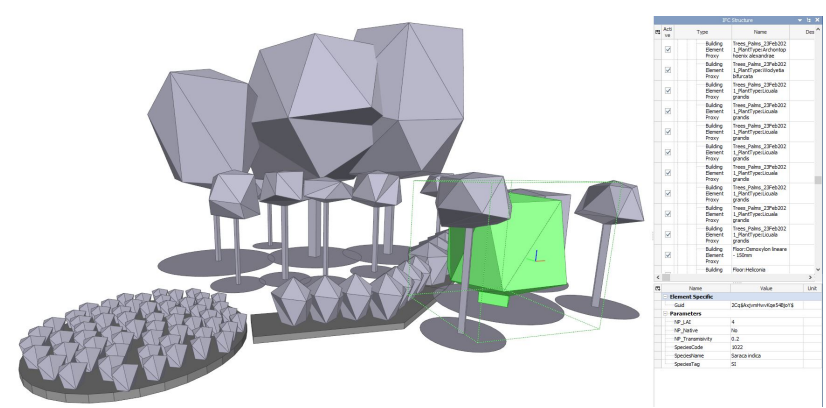

Figure 7. The placeholders are replaced with information-enriched 3D vegetation models.

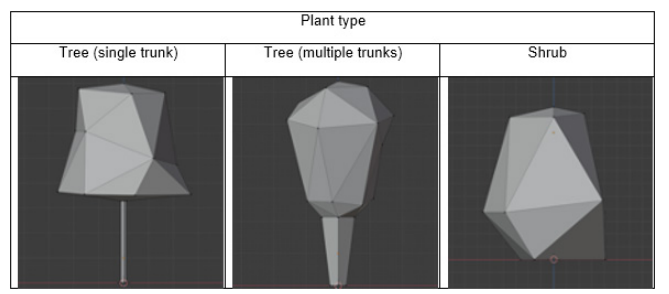

Figure 8. Various shapes and sizes based on spatial parameters

2.4.2 Embedding 3D Vegetation Models into IFC A generated 3D vegetation model, either in the STL or OBJ format, contains facet and vertex information for defining a faceted B-rep model to represent geometric shapes in IFC. As the Brep model is restricted to points, edges and their relation, both OBJ/STL and IFC formatted models are consistent in visualization and more result convertible.

Unlike CAD, an IFC file includes much more hierarchical and non-geometrical information. Placeholders in the IFC file are designed to provide simplified spatial information of hierarchy and location of the vegetation. For solitary trees and palms, the placeholder is a circular object whose center coordinate represents the location of an individual tree. A generated 3D vegetation model will then replace this placeholder. As for shrubs, which are typically planted as a group of individual shrubs to cover an area, more coordination is required in extracting the exact area to populate with the shrub objects, and Section 2.4.3 will explain this in detail.

In addition, all non-spatial parameters (CP and NP) are included in the IFC property set, which is a dynamic container class of properties in an IFC file.

\subsubsection{Automatic Placement of Shrub Vegetation Objects} onto IFC Placeholders Unlike solitary trees and palms which can be located individually by their coordinates, shrubs are planted as a group of individuals in an area. Hence, there are two constraints in the placement of shrubs: the bounding size of an individual shrub object based on its spatial parameters, and the inter-object distance (PlantingDistance parameter). As such, to automatically populate a given area with shrub objects, the top surface of the shrub's placeholders is first extracted (Figure 9) to form an input to the automatic placement algorithm. The input is a series of connected lines in 3D forming a closed loop that defines the top surface extracted earlier. Assuming that plants grow upright, the plant placement problem can be projected to a $2 \mathrm{D}$ plane, solved, and then projected back to the corresponding $3 \mathrm{D}$ plane.
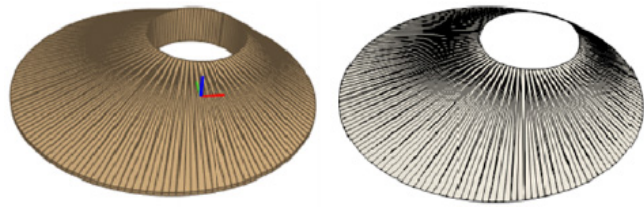

Figure 9. Shrub placeholder (left) and extracted surface (right)

An automatic vegetation placement can be thought of as a mesh smoothing problem, where each plant is represented by an internal vertex, and plants are interconnected in an optimal mesh configuration which is subjected to forces changing the position of the vertices. The first force comes from the boundaries formed by user-defined constraints. This force causes a vertex to be always at a half of bounding size of the plant model, which would not exceed the user-defined constraint boundary upon placement. The other force is the PlantingDistance, which restricts edges between internal vertices to this minimal length.

To setup the placement, 2D boundaries of the planting area are first discretised into regular segments, each of whose lengths is a fraction of the bounding size of the plant model. An internal Delaunay triangulation is then performed, where a new vertex is placed at the mid-point of each edge whose length exceeds a threshold distance. For edges between border vertices, the threshold distance is two times the bounding size of vegetation model. For edges between internal vertices, the threshold distance is the planting distance. For other remaining edges, the threshold is the bounding size plus planting distance. Typically, a relaxation factor $(\leq 1)$ is multiplied with these threshold distances.

The entire mesh configuration undergoes mesh smoothing operation, but it is subjected to edge distancing constraints which project forces to direct vertices to the next positions until reaching equilibrium. The final positions of internal vertices will be the positions of individual shrubs (Figures 10 and 11).
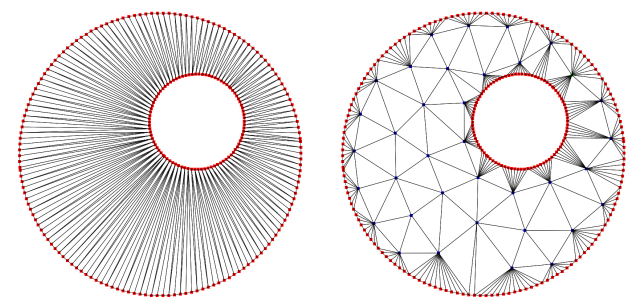

Figure 10. Left: Meshing based on planting distance. Right: Meshing based on model size and planting distance.

\section{RESULTS}

To demonstrate the vegetation library compilation in this paper, five public rooftop gardens, which were constructed over five years ago to ensure their plants had matured, were chosen to extract species level spatial data. These gardens were laser scanned (Figure 12), and plant species were identified in the field and cross-referenced with the scan-generated maps (Figure 13). The spatial parameters were then extracted semiautomatically by using scripts developed in Rhinoceros 3D \& Grasshopper (Figure 14). The tabulated data from this initial scanning exercise was then used to create an initial library of plant species (Table 2), comprising of 26 species of trees or 


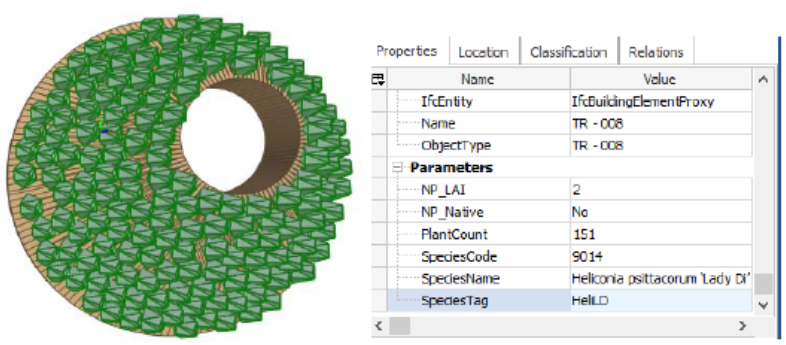

Figure 11. A sample of shrub output IFC model.

palms and 32 species of shrubs in a simple comma-separated values (CSV) format.

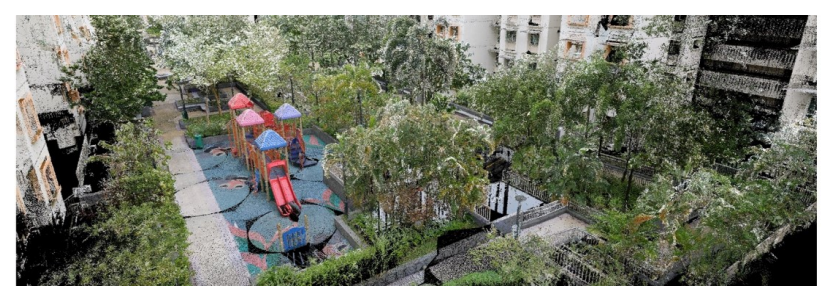

Figure 12. Example outputs of one of the rooftop gardens scanned using the Riegl VZ-400i.

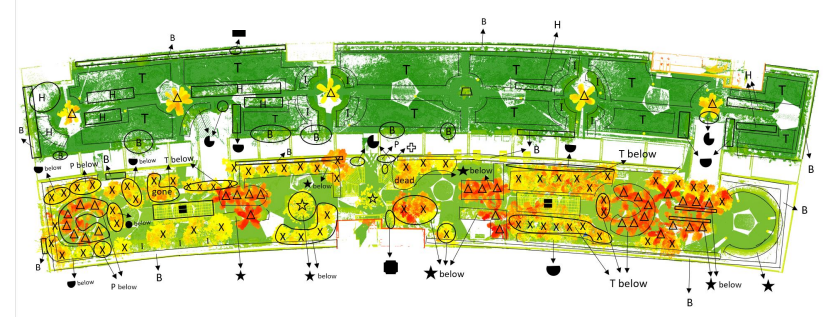

Figure 13. Individual species were identified using maps generated from the scans.

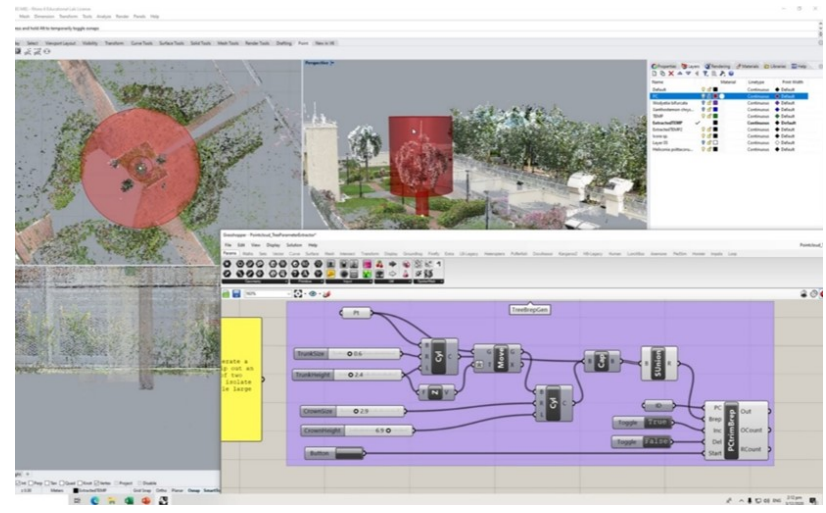

Figure 14. Extracting spatial parameters from individual species identified through the maps and scans.

To simulate a potential real world application by a landscape architect, a simple demonstration of the proposed workflow above was done where a landscape architect would operate a BIM authoring software and export an IFC landscape plan to the IFC interface to embed $3 \mathrm{D}$ vegetation models. As a start, a land- scape plan of a scanned rooftop garden (Figure 13 was recreated in Autodesk Revit 2021 (Figure 15), and it was then exported as an IFC2x3 file to feed into IFC interface through a simple graphical user interface (GUI). The GUI allow users to specify the location of the exported IFC file, the location of the vegetation CSV library, as well as the destination location of output files (Figure 16). The IFC interface would then link the vegetation library and the BIM authoring workflow with the internal automatic processes (3D vegetation model generation and placement); these technical processes operate behind the scenes and are opaque to the landscape architect.

The IFC interface and 3D vegetation model generation are implemented as a fully automatic Python script with IfcOpenShell (IfcOpenShell, 2021), PythonOCC (PythonOCC, 2021), and Blender (Blender Online Community, 2018) support, while the vegetation placement module is implemented in a $\mathrm{C}++$ as a dynamic link library (dll) to be called by the IFC interface. After a user uploads an input IFC file and links the vegetation library, an output IFC file with the embedded vegetation is generated in a few minutes. The running time depends on the sizes and types of specified placeholders in the input IFC file. Specifically, the vegetation placement module runs efficiently in under one second in most test cases (Figure 10) based on the planting area constraints over a range of planting distances between 0.2 to 2.0 metres (Figure 20).

For the sample landscape plan, the developed workflow generated an IFC file containing information-enriched $3 \mathrm{D}$ vegetation models, comprising 101 tree/palm objects and 819 shrub objects (71 shrub clusters on different planting areas), in less than 30 seconds (Figure 17). All user-defined custom parameters were also automatically included into the IFC property sets of the models (Figure 18).

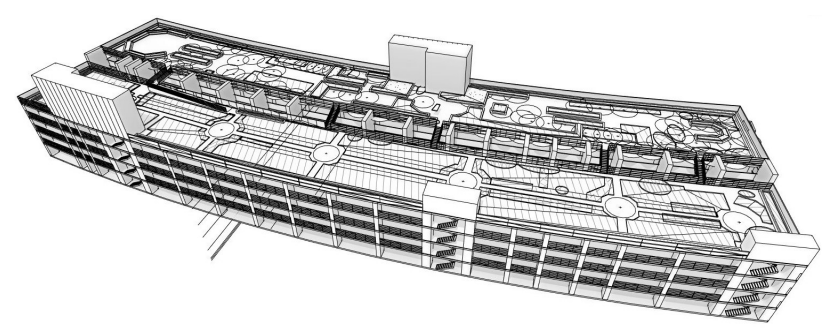

Figure 15. Placeholders in a landscape plan of a rooftop garden.

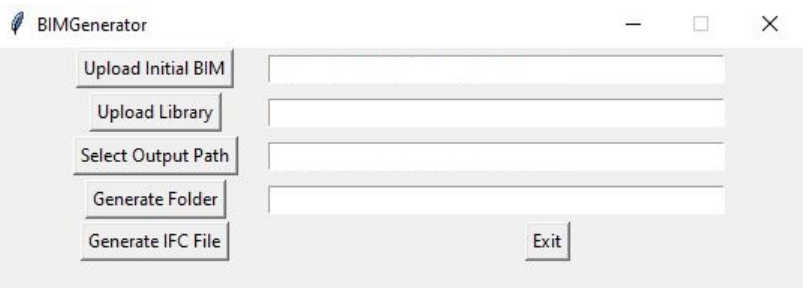

Figure 16. A GUI to interface different data sources.

In addition, the use of IFC format as a common file format between any BIM authoring software and the IFC interface means that this workflow should work for any BIM authoring software as long as its content conforms to the IFC standard (Figure 19). 


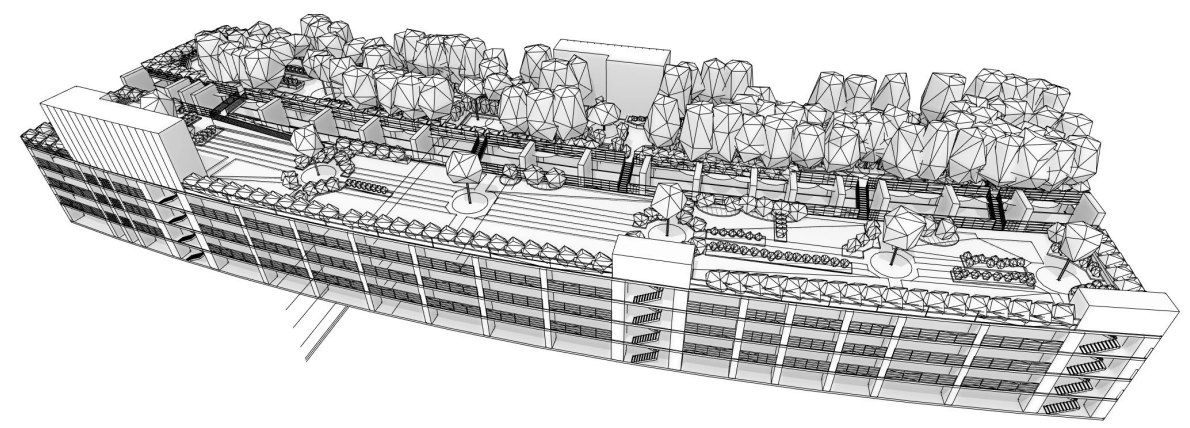

Figure 17. The information-enriched 3D vegetation models are imported as an IFC file into Revit.

\begin{tabular}{|c|c|c|c|c|c|c|}
\hline \multicolumn{7}{|c|}{\langle|$F C$ Vegetation_Schedule $>$} \\
\hline A & B & $\mathrm{c}$ & D & $\mathrm{E}$ & $\mathrm{F}$ & G \\
\hline Count & SpeciesName(Parameters) & SpeciesTag & SpeciesCode( & NP_LAI & NP_Nati & CP_Nursery(Param \\
\hline 12 & Bauhinia kockiana & Bauk & 9001 & 2 & Tes & 123 Nursery \\
\hline 16 & Bougainvillea spp. & Bougs & 9003 & 2 & Yes & ABC Nursery \\
\hline 4 & Cordyline fruticosa & CordF & 9006 & 2 & No & ABC Nursery \\
\hline 1 & Cymbopogon citratus & cymbc & 9008 & 2 & No & XYZ Nursery \\
\hline 8 & Duranta erecta 'Variegata' & DuraV & 9010 & 2 & No & XYZ Nursery. \\
\hline 9 & Heliconia psittacorum Lady DF & HeliiLD & 9014 & 2 & No & XYZ Nursery \\
\hline 9 & Kora sp. & wo & 9016 & 2 & No & 123 Nursery \\
\hline 3 & Philodendron 'Gold' & Philg & 9024 & 2 & No & 123 Nursery \\
\hline 9 & Phyllanthus myrtifolius & Phyllit & 9025 & 2 & Yes & \\
\hline 2 & Plumeria rubra & PR & 1018 & 4 & No & ABC Nursery \\
\hline 36 & Wodyetia bifurcata & WB & 1025 & 4 & Yes & XYZ Nursery \\
\hline 63 & Xanthostemon chrysanthus & $\mathrm{Xc}$ & 1026 & 4 & No & 123 Nursery \\
\hline
\end{tabular}

Figure 18. Imported IFC files with all the custom parameters (CP and NP).

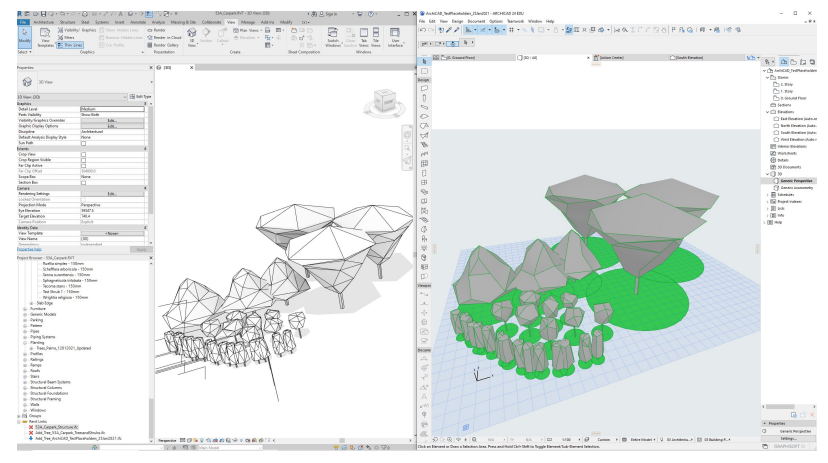

Figure 19. Both Autodesk Revit 2021 (left) and ArchiCAD 24 (right) have been tested for the workflow.

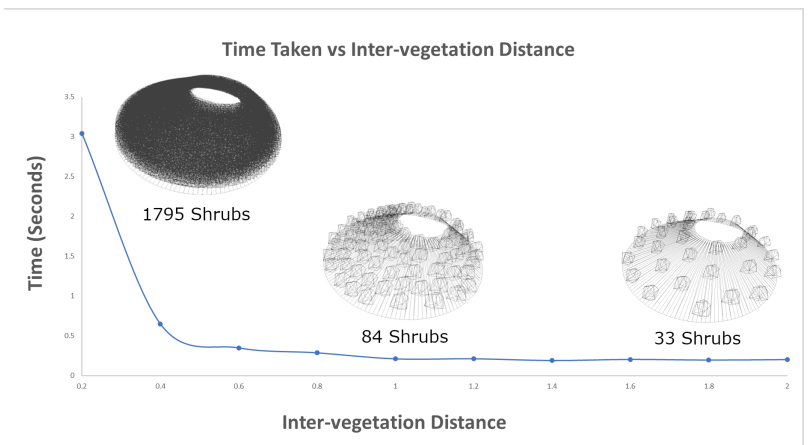

Figure 20. Placement performance with respect to planting distance.

\section{CONCLUSIONS}

The proposed IFC-centric vegetation modelling workflow provides a unified framework of operational modules: an ex- pandable, easy-to-maintain species-level vegetation library for governing agencies, a flexible BIM authoring workflow for landscape architects in submitting landscape plans, as well as the technical back-end of IFC interface and 3D vegetation model generation which automatically coordinate different data sources to generate lightweight, information-enriched $3 \mathrm{D}$ vegetation models.

While we have demonstrated a use case of the above workflow, there are still areas for further development. At present, the vegetation library exists as a standalone CSV file on a local computer, although its parameters are can be easily incorporated into existing databases (such as FFW) thanks to its simple tabular structure. In addition, at the time of writing, the placeholders and model generators for plant types other than trees and shrubs, i.e., climbers, green walls, ground cover, and topiary, are still work in progress.

It is also envisioned that the ability to embed custom non-spatial information from either end-users or the governing agency allows the use of the models for beyond visualisation purposes. An immediate future purpose is to automatically calculate the GnPR or other statutory requirements. In addition, we are exploring other use-cases to estimate the cooling potential of different skyrise greening options (He et al., 2021) and to predict maintenance costs.

The proposed BIM authoring workflow for landscape architects were designed to mimic their current practice of drawing landscape plans in traditional 2D CAD. The IFC interface module removes the need of landscape architects to create and maintain their own library of 3D vegetation models, and ensures compatibility of the modelling workflow with any BIM authoring software in use. However, further user tests on the whole workflow are required to enable actual adoption by landscape architects in the practice of statutory BIM submissions.

In conclusion, the novel use of IFC as a coordinating format between otherwise disparate vegetation databases and BIM workflows, that this paper has demonstrated to be efficient and flexible, lays the groundwork to establishing a centralised species-level BIM vegetation library in Singapore context and beyond.

\section{ACKNOWLEDGEMENTS}

This work is part of a research project titled "Developing a Species-level Building Information Modelling (BIM) Vegetation Library" and was supported by the Ministry of National Development through the National Parks Board of Singapore 
[Grant number: R-296-000-203-490]. We would like to thank colleagues at NParks, NUS, and IHPC for their valuable inputs to this paper.

\section{REFERENCES}

Abdirad, H., Lin, K.-Y., 2015. Advancing in Object-Based Landscape Information Modeling: Challenges and Future Needs. 548-555.

Ackerman, A., 2019. The BIM that Binds. Landscape Architecture Magazine, June 2019, 50-63.

Ahmada, A. M., Aliyua, A. A., 2012. The Need for Landscape Information Modelling (LIM) in Landscape Architecture. Peer reviewed proceedings of the 13th Digital Landscape Architecture Conference, 531-540.

BCA, 2013. BIM Essential Guide - For BIM Adoption in an Organization.

BCA, 2016a. Building Information Modeling (BIM) eSubmission.

BCA, 2016b. Changes to Building Information Modelling (Bim) E-Submission Requirements For Plan Submission To BCA.

Blender Online Community, 2018. Blender - a 3D modelling and rendering package. Blender Foundation, Stichting Blender Foundation, Amsterdam.

buildingSMART, 2021. Industry Foundation Classes (IFC).

Chan, T. W., 2014. Barriers of Implementing BIM in Construction Industry from the Designers' Perspective: A Hong Kong Experience. Journal of System and Management Sciences, 4(2), 024-040.

Flohr, T., 2011. A Landscape Architect's Review of Building Information Modeling Technology. Landscape Journal: design, planning, and management of the land, 30, 169-170.

Gobeawan, L., Lin, E. S., Tandon, A., Yee, A. T. K., Khoo, V. H. S., Teo, S. N., Yi, S., Lim, C. W., Wong, S. T., Wise, D. J., Cheng, P., Liew, S. C., Huang, X., Li, Q. H., Teo, L. S., Fekete, G. S., Poto, M. T., 2018. Modeling Trees for Virtual Singapore: From Data Acquisition To CityGML Models. The International Archives of the Photogrammetry, Remote Sensing and Spatial Information Sciences, XLII-4-W10, Copernicus GmbH, 55-62.

Gobeawan, L., Wise, D., Alex Thiam Koon, Y., Wong, S., Lim, C., Lin, E., Su, Y., 2019. Convenient Tree Species Modeling for Virtual Cities. 304-315.

Gobeawan, L., Wise, D., Wong, S., Yee, A., Lim, C., Su, Y., 2021. Tree Species Modelling for Digital Twin Cities. 17-35.

Graphisoft, 2021. Free parametric BIM Models of "plant" in GDL, 3DS, DWG and DXF formats.

He, Y., Lin, E. S., Tan, C. L., Tan, P. Y., Wong, N. H., 2021. Quantitative evaluation of plant evapotranspiration effect for green roof in tropical area: A case study in Singapore. Energy and Buildings, 241, 110973.

IfcOpenShell, 2021. The open source ifc toolkit and geometry engine.
Landscape Institute, 2019. Building information modelling (BIM) $\mid$ Landscape Institute.

NBS, 2021. NBS National BIM Library - Free to download BIM objects.

Neo, B. S., Gwee, J., Mak, C., 2012. Growing a City in a Garden. Routledge.

Ng, J. S., Nathan Charles, R., 2017. More green spaces in highrise buildings targeted for Singapore's concrete jungle.

NParks, 2021. Flora Fauna Web.

Nyuk Hien, W., Puay Yok, T., Yu, C., 2007. Study of thermal performance of extensive rooftop greenery systems in the tropical climate. Building and Environment, 42(1), 25-54.

PythonOCC, 2021. Pythonocc - 3d cad/cae/plm development framework for the python.

Schmidt, L., 2016. BIM and Landscape Architecture: What, Why, and How?

Siebelink, S., Voordijk, H., Endedijk, M., Adriaanse, A., 2021. Understanding barriers to BIM implementation: Their impact across organizational levels in relation to BIM maturity. Frontiers of Engineering Management, 8(2), 236-257.

Sini, R., 2020. Singapore's Green Infrastructure and Biophilic Urbanism. R. Sini (ed.), Singapore's Park System Master Planning: A Nation Building Tool to Construct Narratives in PostColonial Countries, Advances in 21st Century Human Settlements, Springer, Singapore, 211-251.

Sipes, J. L., 2014. Integrating BIM Technology Into Landscape Architecture. American Society of Landscape Architects.

Tan, A., Chiang, K., 2009. Vertical Greenery for the Tropics. National Parks Board, Singapore.

Uijtdewilligen, L., Waters, C. N.-H., Aw, S., Wong, M. L., Sia, A., Ramiah, A., Wong, M., Müller-Riemenschneider, F., 2019. The Park Prescription Study: Development of a communitybased physical activity intervention for a multi-ethnic Asian population. PLOS ONE, 14(6), 1-24.

URA, 2017. Guidelines for landscape replacement areas within new developments and redevelopments in identified strategic areas. 